\title{
La sociolingüística de los medios de comunicación
}

\author{
Antonio María López González (Posnan)
}

\begin{abstract}
This article shows the different kinds of approaches to the mass media from the sociolinguistics, and the meaning of these studies for the society itself. A variety of points of view and topics studied by authors throughout the world conform the sociolinguistic works on mass media. Several topics are discussed about press, radio and television: sociolinguistic prestige, linguistic uses in the media, production, product, reception, linguistic interaction, standardization, interaction between media and audience, media manipulation, didactic applications of the media, etc. The author presents a wide review of the works published in the last years on this issue. The article is accompanied by a long, comprehensive bibliographic chapter which indicates the studies of the sociolinguistics of mass media.
\end{abstract}

La importancia social de los medios de comunicación y su influencia en la población es un factor de primer orden en la conformación de la sociedad actual. En la llamada "Era de la Información" en que vivimos, prensa, radio, televisión, e Internet acercan hasta el último rincón de la sociedad humana un conocimiento enciclopédico global, que incluye, entre otros, un conocimiento sociolingüístico, lo que a su vez modifica el mapa sociolingüístico general y los mapas sociolingüísticos particulares en un proceso dialéctico.

A este tenor, y de entre las diferentes funciones de los medios de comunicación expuestas por Lucas (1976), subrayamos desde un punto de vista sociolingüístico la función de conferir prestigio a determinados modelos lingüísticos que la audiendia imita. Es por esto por lo que los medios de comunicación de masas son uno de los vehículos fundamentales de la estandarización lingüística.

De hecho, García Marcos (1995: 35) afirma que las actuaciones lingüísticas de los profesionales de la información y la de quienes, desde fuera del periodismo, intervienen en ellos (entrevistados, participantes en debates, etc.) son susceptibles de ser aceptadas como tales modelos. Y ello debido al papel de forjadores de patrones sociolingüísticos que los medios tienen, como ha quedado de manifiesto en el caso de la estandarización de la "pronunciación recibida" (R.P., Received Pronunciation) del inglés de la BBC (Leitner, 1979), o en los comportamientos lingüísticos de los medios en este siglo en Italia (Klein, 1986; Sobrero, 1971).

El lenguaje de los medios de comunicación posee el doble carácter de hecho lingüístico, por cuanto que es lenguaje, y de hecho social, puesto que se da en una institución social que opera dentro de la sociedad. Por ello, lo podemos catalogar como hecho sociolingüístico, un hecho lingüístico en su contexto social fruto de la relación entre una estructura social y una estructura lingüística (Moreno Fernández, 1990: 26). 
En nuestra opinión, la manera más apropiada de estudiar exhaustivamente un hecho sociolingüístico es desde la Sociolingüística y con una metodología sociolingüística. La perspectiva sociolingüística y la metodología que le es propia proporcionan el marco ideal para los estudios acerca del uso de la lengua en los medios de comunicación social, con todas las características que le son inherentes en cuanto tales, y las variedades lingüísticas en ellos empleadas. En los albores de la disciplina sociolingüística, Fishman (1972: 35-37) ya notó la importancia sociolingüística de los medios de comunicación, abundando en la cuestión del contenido sociolingüístico que la lengua comunica:

"Los titulares periodísticos con todas sus estridencias pueden servir para
mentalizarnos de una autoevidencia frecuentemente olvidada por muchos
americanos; en otras palabras, que la lengua no es simplemente un medio de
comunicación y de influencia interpersonal. No es simplemente un vehículo
de contenidos, ya latentes, ya patentes. La misma lengua es contenido, un
referente de lealtades y animosidades, un indicador del rango social y de las
relaciones personales, un marco de situaciones y de temas, así como un gran
escenario impregnado de valores de interacción que tipifican toda
comunidad lingüística".

El presente artículo pretende hacer un amplio repaso a los trabajos realizados desde el ámbito de la sociolingüística dedicados al estudio de los medios de comunicación, delimitando los temas más frecuentemente analizados. Para ello, utilizaremos como fuentes de información los estudios de Schmitz (1987), Bell (1991, 1997), Leitner (1996) y los sucesivos números del anuario Sociolinguistica editado por Ammon, Mattheier y Nelde (1987-1999).

El lenguaje de los medios de comunicación representa, según Bell (1991: 1), aquella situación en la que "la minoría habla a la mayoría". La sociedad moderna se halla saturada del lenguaje de los medios. Por ello, la influencia lingüística - e ideológica - de éstos es enorme. Este hecho constituye por sí solo una razón para estudiar el lenguaje de los medios. Bell (1991: 34) abunda en las razones por las que se estudia este lenguaje y cita entre ellas las siguientes:

- La accesibilidad de los medios de comunicación como fuente de datos para estudiar determinadas características lingüísticas,

- El interés por estudiar el lenguaje de los medios de comunicación propiamente dicho,

- El interés por la forma en que los medios usan algunas características lingüísticas también encontradas en el lenguaje ordinario,

- El interés por cómo los medios usan la lengua para comunicar contenidos,

- La superación de la paradoja del observador de Labov (1972: 209), por cuanto que el hablante de un medio público no cambia su forma de hablar aunque esté siendo grabado,

- Etc.

La sociolingüística estudia el discurso de los medios de comunicación en el contexto del dominio de la comunicación y revela, asistida por otras disciplinas lingüísticas y por las ciencias de la información, el funcionamiento de éstos, qué parametros determinan su/s norma/s, lo que el público piensa de este discurso y las funciones que intenta cumplir (Leitner, 1996: 187). Leitner utiliza el término "discurso de los medios de comunicación" para referirse a las formas, estructuras, y usos de la lengua y otros códigos semióticos que son específicos a los medios de comunicación. Esto también se aplica a otros sistemas cognitivos subyacentes, como, por ejemplo, las ideologías (Leitner, 1996: 190). 
La macrosociolingüística o sociología del lenguaje, junto a las Ciencias de la Información, consideran a los medios de comunicación como una institución social (Schramm, 1975; Curran y Seaton, 1991) o como un dominio (Fishman, 1974), McQuail (1983: 39-40).

Utilizando la terminología sugerida por Fishman (1974), para Leitner (1996: 189) los medios de comunicación son dominios de la comunicación con una estructura comunicativa específica, la cual proporciona contenidos que llegan a ser públicos o accesibles tanto al conocimiento como al debate público. El discurso que expresa el contenido ha sido definido por Hall (1978: 48) como un idioma público, que no es -y que tampoco puede ser homogéneo, porque la sociedad tampoco lo es. Más aún, cada medio crea su propia versión. El propio Hall enfatiza: "El lenguaje empleado será así la versión que el periódico hace del lenguaje del público al cual principalmente está dirigido" (Hall, 1978: 48). Martensson (1989), por otra parte, habla de la existencia de un lenguaje privado en público, en el que las barreras de la privacidad se rompen.

En todo caso, hay que afirmar que son muchas las publicaciones en los últimos años que han intentado caracterizar y describir el lenguaje de los medios de comunicación y cómo la sociolingüística ha de estudiarlos. Contamos entre éstas a Jocic (1985) en la antigua Yugoslavia, French (1986) en Irlanda, Sambor (1986) en Polonia, VV. AA. (1989) y Frandsen (1996) en Suecia, Treskova (1989) en Rusia, Hlavsa (1990) en Eslovaquia, Burger (1990) y Schmitz (1995) en Alemania, Alvar (1990) en España, Bing (1991) en Noruega, etc.

Es preciso distinguir el discurso de los medios de comunicación de los mensajes que transporta, nociones que describen el contenido y la forma de artículos o programas. Mensajes y discurso se relacionan de diversas maneras. Desde el punto de vista del proceso de producción, el procesamiento del contenido tiene lugar a muchos niveles o estratos de la jerarquía institucional hasta que se transmite como mensaje de los medios de comunicación. Desde la perspectiva del resultado de esta producción, los mensajes están secuenciados espacio-temporalmente (Leitner, 1996:190).

Así, por un lado, encontramos diferentes formatos de programación (noticias, editoriales, reportajes, etc.), o distintas maneras o estilos de aproximarse a una realidad, de comunicar esa realidad o incluso de crear esa realidad. La cadena COPE realiza esta aproximación de una forma, TVE de otra y El Mundo de otra diferente. Por otro, las características del medio imponen restricciones técnicas a la transmisión de contenidos, condicionando la forma de los mensajes en el espacio y en el tiempo, ya sea en televisión, radio, prensa o Internet.

Es obvio que el progreso tecnológico ha cambiado las condiciones de producción de los medios de comunicación. Contamos con estudios que así lo atestiguan. De este modo, Delamotte (1990) presenta la repercusión de esta innovación tecnológica y de las prácticas de los usuarios en las llamadas industrias de la lengua, Nordberg (1992) trata el mismo tema en la radio sueca indicando la aparición de una nueva oralidad que contrapone la tecnología a la tradición radiofónica. Slembek (1995), por su parte, investiga los elementos retóricos en la producción de los medios. Patras (1996) completa el cuadro de análisis de las condiciones de producción haciendo recuento de los problemas de comercialización en el perfil comunicativo en la esfera de la radio privada.

Otros estudios se dedican a investigar pormenorizadamente casos particulares. Este es el caso de los trabajos de Abend (1974), que detalla los objetivos y condiciones de producción de los noticiarios alemanes, y de Esquenazy (1993) años más tarde, que aborda el mismo tema en la televisión francesa. 
No hay muchos estudios lingüísticos que hayan abordado la evolución de la noción de orientación (estratos de programación) y temática. Cardiff (1980) ha revelado el desarrollo de la distinción entre lo serio y lo popular como conceptos de programación y su manifestación en tipos de programas en la BBC. De otra parte, la historia de la información deportiva ha sido estudiada por Hargreaves (1986) y McChesney (1989).

La mayoría de los estudios lingüísticos de medios de comunicación se han ocupado del análisis de córpora de noticias, reportajes y otros géneros periodísticos con el objetivo de analizar léxico particular o características gramaticales propias y/o típicas de los medios de comunicación. Ejemplos de estos estudios son los trabajos de Virtanen (1992) acerca del la posición en la frase de los adverbios o el estudio del género "noticias" de Bell (1991). Bentele (1985) sugiere una "gramática" para los programas de noticias basándose en un corpus alemán. Las estructuras discursivas de las entrevistas (formando parte de programas o siendo parte de ellos), llamadas telefónicas del público, presentaciones y debates han sido identificadas en Scannel (1991), Leitner (1983a), Heritage (1985) y Trösser (1983). Van Dijk (1988b) ha sugerido un modelo de macrotexto para los reportajes de la prensa internacional. Desde una perspectiva más amplia, la variación lingüística según estilos de programación es tratada por Ball (1985). Por otra parte, basándose en reportajes de fútbol en la prensa alemana, Simmler (1993) estudia la tipología de estos textos a partir de su disposición. Mislovicova (1994) hace otro tanto sobre los comentaristas deportivos en televisión. Otras características de los textos de medios de comunicación también han sido estudiadas por Graustein y Thiele (1987) y Werlich (1976).

Muchos de los temas investigados desde la Lingüística en general - y sociolingüística en particular - tienen un tratamiento equiparable en cada medio, lo que ha dado pie a Zilbert (1986) a presentar conjuntamente distintas investigaciones sociolingüísticas de textos de radio, televisión y prensa en un trabajo publicado en ruso. No obstante, las características técnicas de cada uno de los medios de comunicación hacen necesarios estudios particulares del uso de la lengua en cada uno de ellos. Así podemos distinguir claramente las siguientes investigaciones:

- A) Estudios del lenguaje de los periódicos. A su vez se diferencian:

1. Investigaciones de carácter general, en los que se trata de caracterizar y definir las características propias del lenguaje de los periódicos: Medici y Proietti (1992) y Farago Leonardi (1993) en Italia, Martínez Albertos (1990) en España, Dhrimo (1990) en Albania, Straßner (1997a, b) en Alemania, etc.

2. Investigaciones particulares. Entre ellas contamos el análisis del léxico periodístico en España realizado por Alcoba (1998), el artículo de Martínez Marín (1993) caracterizando el lenguaje periodístico, el estudio de Fiala y Habert (1989) de los titulares de la prensa diaria francesa y de Kniffka (1980) de los titulares periodísticos y la formulación del lead periodístico en la prensa americana, el análisis de Fasold et alii (1990) de los editoriales del Washington Post, los trabajos de Petrović (1989b) sobre la fraseología en los periódicos de la antigua Yugoslavia y los comentarios en la prensa (Petrović, 1989a), el estudio de Wagn (1989) acerca de los usos lingüísticos en el periodismo de países del tercer mundo, la investigación de Braćić (1993), en que da cuenta de la penetración del lenguaje cotidiano en los reportajes periodísticos como consecuencia de una función comunicativa de la prensa alemana actual, el manual de Roksvold (1989) sobre la retórica de los periodistas en Noruega. 
- B) Estudios del lenguaje radiofónico.

1. Estudios generales son los de Balsebre (1994) y Huertas Bailén (1999) en España, Roncagliolo (1997) y Romo (1997) para el mundo hispánico, Paananen (1996) en Finlandia y Sadow y Sather (1998) para el mundo anglosajón.

2. En cuanto a los estudios particulares, la bibliografía es ingente. A modo de ejemplo mencionamos la descripción de Cervignón y otros (1977) del nuevo lenguaje de las noticias en la radio, el artículo de Vagle (1991) en el que dirime la calidad de lenguaje escrito o hablado del lenguaje radiofónico, el estudio de Nordberg (1992) acerca de las formas de expresión femenina en la radio, la discusión de Einarsson (1994) sobre la aparición de la "privacidad pública" en la radio local, el análisis de Sandøy (1996) de la tensión norma linguiística - variación lingüística aceptable en la radiotelevisión noruega, o el estudio de Åbrink (1996) sobre el papel del locutor de radio, la investigación de Weber (1989) sobre la morfosintaxis del alemán en la radio, la descripción del lenguaje radiofónico de Columbus, Ohio, de Hinskens et alii (1997). Citamos además a Barahona Novoa (1996), que estudia el léxico básico de la radio costarricense y a Gutiérrez (1979), que investiga el uso de la lengua española en el suroeste de los Estados Unidos, etc.

- C) Estudios del lenguaje televisivo.

1. Son estudios de índole general los de Tsonev et alii (1996) en Bulgaria, Holly y Püschel (1996) en Alemania, Diadori (1994) y Raffaelli (1994) en Italia y Jonsson (1989) en Suecia.

2. Los estudios particulares son muy numerosos. Aparte de numerosas investigaciones desde un punto de vista más semiótico, censamos a modo ilustrativo el estudio de los belgas Ballstaedt y Esche (1976) sobre la relación entre texto, contexto e imagen, y sus efectos en la recepción del televidente. Este mismo tema es tratado por Ensink (1997), quien hace un estudio de un reportaje de la televisión holandesa sobre un político sospechoso de corrupción. Holly (1992) analiza la especificidad del lenguaje del programa-espectáculo de la televisión alemana del sábado por la noche "Die Samstagabend-Fernsehshow". Esquenazy (1993) se ocupa de los problemas de producción de los noticiarios de la televisión francesa. Este género, el de los noticiarios televisivos, ha sido objeto de cuantiosos estudios. Diadori $(1992,1993)$ analiza la lengua de los noticiarios televisivos italianos de los años 90. Povażaj (1993) hace otro tanto en Eslovaquia. Straßner (1982) hace un análisis del proceso de producción el resultado de éste - producto - y la recepción de los noticiarios televisivos en Alemania. Giacomelli (1992) se ocupa del lenguaje de los noticiarios para jóvenes en Italia. Las lecturas que de estos noticiarios se hacen han sido tratadas por Carl (1991). Los comentarios en televisión también han ocupado frecuentemente a los investigadores: Sliwinski (1986) en Polonia, con un carácter general, Halwachs (1991) en Alemania con atención al estilo de los comentarios políticos con fines persuasivos, o el ya mencionado Mislovicova (1994) en la República Checa acerca de los comentaristas deportivos. Otros temas investigados han sido de carácter léxico, como el estudio léxico-estadístico del español hablado en televisión de Ortega Olivares (1979), y especialmente en Polonia con los estudios de Kubiszyn-Mędrala (1992) y Ligara (1992) sobre el vocabulario más frecuente en la televisión polaca; o el reportaje del Nordisk Språksekretariat (1989) sobre el uso de subtítulos en la televisión noruega, etc. 
Otro tipo de estudio recurrente es el análisis de un tema específico dentro de un formato de programa durante un período de tiempo. Ejemplos de esto son los estudios de Fowler (1991) acerca del cuidado de la salud, la ley, el orden público y el sexo, Walton y Davis (1983) sobre el asesinato de un presidente italiano, Van Dijk (1988a) tratando el asesinato del presidente Gemayal, los cuales descubren modelos y prácticas periodísticas en la codificación y decodificación de los mensajes. Sorenson (1991) analiza el llamado discurso sobre el hambre en el Cuerno de África y Triandafyllidon (1995) describe el tratamiento del accidente de Chernobyl en la prensa italiana. Valić Nedeliković (1997b) investiga el lenguaje de los reportajes de la radio serbia desde los campos de batalla en los balcanes y los juramentos en los medios de comunicación en general Valić Nedeliković (1997a). De otra parte, Ferguson (1983) estudia cómo afectan diferentes características sintácticas al estilo de los reportajes deportivos en América.

Un tema especialmente investigado, sobre todo por la sociolingüística escandinava, Strand (1992) en Suecia, Nuolijärvi y Tiittula (1995) en Finlandia, alemana (Penz, 1994b/1996), y británica es el de la interacción lingüística en los medios radiofónicos y televisivos. También en Italia Cortese y Potesta (1987) estudian las estrategias de los participantes en un debate radiofónico, así como otro tanto hace Muller (1995) en Francia. En estos estudios, el sociolingüista se interesa entonces por el modo en que interactúan comunicativamente los participantes en debates, discusiones o entrevistas en estos medios.

Alemania ha ofrecido a la sociolingüística un amplio abanico de estudios al respecto. Focalizando la atención en aspectos más particulares, Gruber (1992) se interesa por la estructura y el reparto de papeles en los debates en televisión, y Holly, Hühn y Puschel (1986) se ocupan de los debates políticos televisados y su escenificacación como propaganda. En relación con esto en la misma escuela alemana Felderer (1990) analiza la amabilidad lingüística en entrevistas con políticos. Los irlandeses Greatbatch (1986) y Harris (1986) preceden a su homólogo alemán Penz (1994a) analizando los diversos tipos de preguntas en las entrevistas y debates.

En la escuela escandinava, a los ya citados trabajos de Strand (1992) y Nuolijärvi y Tiittula (1995), hay que sumar los de los mismos autores Strand (1991), en el que investiga cómo afecta el sexo y el contexto social del hablante al dominio de una entrevista en televisión y el de Nuolijärvi y Tiittula (1997) sobre las características, estructura y propósito de una agenda en conversaciones en television.

En la escuela británica destacan por su singularidad y actualidad los trabajos de Hawkins (1989) sobre la fluidez en las entrevistas de radio y el de Hutchby (1996) acerca de las manifestaciones de las relaciones de poder en el discurso.

Un tipo de análisis diferente se refiere a la política lingüística y a las actitudes. Por medio del análisis de los diversos tipos de programas se descubren las fuerzas sociales e institucionales que se hallan tras la formulación y las formas de realizar estos programas (Leitner, 1980a, 1984).

Los medios de comunicación dependen de sus fuentes - dominios sobre los que informan (política, ciencia, deportes, música, etc.), en terminología de Leitner (1992: 56). Esta dependencia afecta no sólo al contenido informativo, sino también al lingüístico. Los medios de comunicación deben procesar los sistemas cognitivos, las normas lingüísticas, las prácticas profesionales y los registros de estos dominios. Este procesamiento puede significar integración, supresión, o modificación (Leitner, 1996: 193), o incluso puede llevar junto a 
estos también a procesos semánticos de selección, resumen y generalización ya estudiados por Van Dijk (1988a). Por otro lado, GUMG (1980), Fowler (1991) y otros han llevado a cabo una clasificación jerárquica de las fuentes, distinguiendo fuentes autorizadas y fuentes no autorizadas, basándose en la frecuencia con la que éstas son citadas, lo cual afecta, además al procesamiento lingüístico de la información. Bell (1991) ha estudiado los pasos de este proceso de elaboración en el caso especial de las noticias, desde la recepción de éstas suministradas por las agencias hasta su emisión y los problemas que se plantean en este proceso y de cara a su recepción.

Un segundo aspecto estudiado en cuanto a las fuentes es la adopción de léxico propio de los dominios sobre los que se informa por parte de los medios de comunicación. Ejemplos de esto son Hartley (1982), Fowler (1991) acerca de la adaptación ideológica de lenguajes específicos, Staczek (1993) sobre el uso de lenguaje militar en los reportajes de la Guerra del Golfo o Siehr (1993), el cual trata del uso de lenguaje legal durante el proceso de la reunificación alemana. Hemos de mencionar así mismo los análisis de Simmler (1991, 1993) sobre la relación del lenguaje de los deportes con los del lenguaje de los reportajes de la prensa deportiva, Hess-Lüttich (1983) del alemán usado en prensa para adolescentes.

Dentro del proceso comunicativo que nos ocupa, los receptores de los mensajes de los medios de comunicación han sido también objeto de estudio por parte de la sociolingüística. Uno de los conceptos más interesantes al respecto es el de estilo de la audiencia ("audience design") investigado y desarrollado por Bell (1991). Bell (1984b, 1990) ha demostrado que las decisiones encaminadas a la selección y codificación de expresiones lingüísticas tienen un correlato con los parámetros sociales de la audiencia.

El hablante, conscientemente o no, escoge un nivel estilístico apropiado a la audiencia a la que él o ella desea dirigirse. La noción viene de los locutores de radio que acomodan su estilo al de su audiencia. El mismo locutor utiliza distintos estilos cuando lee las noticias en una emisora de proyección nacional, y cuando presenta una canción en una emisora de música popular. Al seleccionar un estilo apropiado a una audiencia particular, el locutor se está identificando con esta audiencia y está llamando la atención acerca de su pertenencia al grupo que la constituye (Spolsky, 1998: 41-42). En relación con esto último, Coupland (1985) y Montgomery (1988) investigan los recursos lingüísticos que los presentadores utilizan para crear una relación con la audiencia.

Por su parte, Noelle-Neumann et alii (1994) investiga cómo los medios de comunicación llegan al conocimiento de sus receptores. A éste se llega no sólo a través de cartas, llamadas telefónicas, etc., sino por medio de estudios empíricos de las mismas empresas. De hecho, la $\mathrm{BBC}$, tras constatar las preferencias linguiísticas de su audiencia acomodó su lenguaje a éstas, evitando utilizar un lenguaje para élites (BBC, 1979).

Los medios son parte constituyente de la sociedad, y como tal, deben servir a ésta. Burger (1990: capítulo 8) en un estudio empírico sobre la comprensión de los mensajes de los medios concluye que estos fallan en su función de transmitir información, porque los mensajes son difíciles de entender para determinados sectores de la audiencia. La recepción de los mensajes de los medios y, en especial, su comprensión, ha sido objeto de estudio reiteradas veces por parte de la sociolingüística. Sobre esto podemos distinguir dos tipos de estudios: 
- A) los dedicados a analizar el grado de comprensión de los mensajes de los medios. Éstos estudios se han centrado especialmente en el análisis de la comprensión de las noticias en televisión - y radio - desde una perspectiva crítica, relacionando texto, contexto e imagen, y su recepción por parte del radioyente o televidente (Ballstaedt y Esche, 1976; Bosshart, 1976; Hutz et alii, 1977; Ballstaedt, 1980; Lutz y Wodak, 1986, 1987, Mårtennsson, 1990). Hinkelbein (1977) se ocupa, por su parte, de la influencia que la forma de hablar de los locutores tiene en la comprensión y formación de opinión de los receptores. Dentro de este tipo de estudios, Heinrich (1981) estudia la comprensión del verbo y del sujeto en los titulares periodíticos.

- B) Los dedicados al proceso de percepción cognitiva de los mensajes, en función del contexto cultural y social o de la situación personal. En este punto destacan los trabajos de Davis y Vincent (1986) acerca de la percepción de noticias sobre desastres, el trabajo de Carl (1991) sobre las diferentes lecturas de las noticias de televisión o el estudio de Palsbro (1995), en el que plantea la diferente percepción de un anuncio de televisión de un danés y un español.

Pasando a analizar los estudios relativos a la producción de los mensajes en los medios, Leitner (1996: 195), señala que es preciso distinguir el cómo o presentación (estilo) del qué o representación (contenido) de éste. Las elecciones lingüísticas que el profesional de los medios de comunicación hace expresan valores como la inmediatez o la distancia, compromiso o imparcialidad, objetividad o dramatización. Estos valores dan una marca de identidad al producto mediático. Por lo que respecta a la representación, ésta forma parte de la postura ideológica del medio correspondiente. Especialmente interesante al respecto es el estudio de Kress (1983). Éste subraya la interrelación de los procesos lingüísticos e ideológicos, los cuales afectan tanto a la forma como al contenido (Kress, 1983: 44-45), postura ratificada con posterioridad por Fowler cuando afirma que la parcialidad se manifiesta "no sólo en qué afirmaciones y actitudes se comunican - una cuestión de contenido - sino también en cómo se comunican - una cuestión de forma o estilo" (1991: 23).

La presentación tiene que ver con la estandarización, esto es, los procesos de selección, codificación, expansión, y aceptación de alguna variedad de expresión lingüística (Leitner, 1996: 196).

La elección de una lengua aparece con frecuencia en países plurilingües, en medios de comunicación para grupos lingüísticos minoritarios, o de distribución internacional o extranacional. Sobre esto, Fox (1991) describe elecciones lingüísticas en situaciones competitivas y la propagación de lenguas minoritarias analizando la situación del irlandés, el islandés, el gaélico y el checo entre otras lenguas, mostrando los beneficios del apoyo tecnológico y de la producción de los medios. Lowander (1986) estudia la influencia lingüística mutua de los medios de comunicación suecos y finlandeses. Lo y Wong (1990) describe situaciones de poliglosia en los medios escritos cantoneses de Hog Kong. Omdal (1995) indaga en la problemática que conlleva utilizar el dialecto nativo en los medios de comunicación, Ruf (1996) se ocupa del caso especial del dialecto de Glasgow en la BBC de Escocia y en Radio Clyde.

La América andina y central representa un caso singular en el contexto que discutimos. Todavía la radio representa el medio más eficaz para comunicarse entre sí y con el exterior por ser una zona deprimida. Las comunidades indígenas constituyen entre el 50 - 55\% de la población en países como Guatemala (del Aguila, 1987; Simon, 1987; Stewart, 1981, 1984; Suarez, 1983), donde existe una situación de diglosia entre el español y las lenguas indígenas. Por esto es precisamente interesante determinar la efectividad de la comunicación radiofónica. 
Los estudios de Cojtí (1983) y Moore (1989) sobre la situación radiofónica de Guatemala, y de Albó $\left(1977^{2}\right)$ sobre la de Bolivia muestran dos procesos opuestos en la radio de estos países:

a) uno castellanizante, represivo frente a las culturas indígenas, que no constituye una comunicación intercultural

b) y otro a través de nuevas experiencias radiofónicas en las lenguas aymara y quechua que contribuye " a forjar la identidad y solidaridad" de estos grupos étnicos (Albó, 1977²: 30).

Sin embargo, el caso más frecuente de estandarización es el de la elección de una variedad dentro de una lengua. Fishman (1974: 1644) afirma que "la variedad estándar es la más 'segura' para aquellas comunicaciones en las que el hablante no puede conocer a sus diversificados y numerosos oyentes".

Un caso ejemplificador de normalización lingüística es el italiano. Berruto (1979: 155-157) constata como la difusión de una lengua nacional en detrimento de los restantes dialectos italianos se realiza a través de las redes oficiales de comunicación y por medio de los medios de comunicación masivos. Ésta difusión a través de los medios se basa en su "importancia socio-ideológica - típica de sociedades industriales modernas", controlada por élites socioeconómicas. El poder estandarizador de los medios de comunicación, superior al que la escuela puede efectuar por medio de su instrucción, parte del "hecho de que no se dirigen institucionalmente a esa finalidad educativa y por el de alcanzar al ususario en su esfera privada y de tiempo libre, cuando está más expuesto a la acción no oficial de tales medios" (Berruto, 1979: 170).

Abundando en el tema de la estandarización, Leitner (1980a) compara las políticas lingüísticas de la radio alemana y británica. En Gran Bretaña la variedad estándar dominó tanto tiempo como el dominio socioeconómico y político fue monopolizado por el sudeste de la isla, de donde ésta procedía, mientras que en Alemania, la organización del país en estados federados favoreció la vitalidad de las distintas variedades regionales también en la radio. Otros estudios analizan la política lingüística en los medios de Nueva Zelanda (Bell, 1983) y Australia (Leitner, 1984), mostrando las tensiones entre las variedades vernaculares del inglés y las internacionales en estos medios. Con respecto al mundo hispánico, Ávila (1997a) estudia la influencia de la radio y la televisión en las normas lingüísticas nacionales e internacionales en el marco del proyecto DIES-RTP para definir un español internacional para los medios de comunicación via satélite.

En cualquier caso, son muchos los trabajos que se encargan de investigar la corrección lingüística en los medios de comunicación y el papel de estos como modelos lingüísticos. Aquí nos ocupamos solamente de aquellos que tratan el tema desde una perspectiva meramente descriptiva. Entre ellos, Videnov (1987) estudia la corrección lingüística en los medios de comunicación bulgaros, Del Canto (1987) analiza la influencia de la televisión en el habla de los jóvenes, quienes, según él, siguen cada vez más el modelo lingüístico utilizado en ella. El Diari de Barcelona (1987) edita un modelo de lengua catalán para los medios de comunicación. En una onda similar aparecerían posteriormente los libros de estilo de la Agencia EFE (1989), El País (1990) o ABC (1993). Rojas (1989) estudia la norma y uso de la lengua a través de la prensa escrita argentina. Del mismo tema se ocupan Jonsonn (1989) con relación a los medios suecos, Sandøy (1996) con respecto a la radio y televisión noruegas, Pavlou (1997) investigando los medios chipriotas y Gheţie (1994) describiendo la norma rumana de la radio. Finalmente mencionamos a Paananen (1996), quien investiga el uso de un finlandés estándar frente a las diferentes variedades de esta lengua en la radio de este país. 
Un factor importante en relación con la codificación lingüística, es la procedencia de las noticias de agencias internacionales que utilizan el inglés como vehículo de comunicación. Se han realizado diversos estudios acerca de cómo el inglés internacional influye en los medios nacionales tanto en la traducción como en el uso de anglicismos. Sirvan como ejemplo los trabajos de Simpson (1985) sobre la situación en Nigeria, Nihalani et alii (1979) y Bansal y Harrison (1983) refiriéndose a la India, Vaquero (1990) investigando la prensa de San Juan de Puerto Rico o Hussein y Zughoul (1993) tratando el caso de la prensa árabe.

Hay que subrayar, finalmente que ha sido puesta de manifiesto la correlación entre la producción de los medios, la comunidad de habla, el tiempo, el tipo de audiencia y los dominios sobre los que se informa en Bell (1991: 130 y ss.; Jucker, 1992). Correlaciones entre estructuras discursivas, normas de presentación y objetivos de los medios han sido señalados, entre otros, por Burger (1990) y Scannel (1991). El propio Bell (1984a: 87) ya había descubierto la presencia de modelos de variabilidad en la edición de noticias.

En relación con el contenido - representación - en terminología de Leitner (1996), la manera en que este se selecciona y las palabras, imágenes, sonidos, etc. con que se nos transmiten afectan a la forma en que concebimos e interpretamos la realidad, lo que se relaciona con una determinada postura ideológica adoptada por el medio, como quedó dicho con anterioridad. Cómo se seleccionan y se transforman las noticias es estudiado en Bell (1991: 155-160). Fowler et alii (1979), GUMG (1980) y Fowler (1991) analizan el papel categorizador y mediador de los medios con respecto a la realidad sobre la que informan.

Huth (1977) investiga las relaciones entre el suceso, la objetividad informativa y la manera en la cual la noticia es presentada en televisión. Good (1985) se ocupa del mismo asunto en la prensa alemana. Hinkelbein (1977) aborda las consecuencias de un determinado estilo lingüístico en la comprensión y en la formación de una opinión. En clara contraposición con la pretendida objetividad o implícita subjetividad, Jansen y Verhoeven (1995) desvelan las técnicas de la falacia informativa.

La lengua y los medios comparten al mismo tiempo el papel de espejos de la vida social en palabras de Estrella (1989). En los medios se refleja la ideología y la cultura de una sociedad (Dobroczyński, 1996), los conflictos de esa sociedad - también en el lenguaje empleado (Wozniakowski, 1996). Ello ha sido puesto de manifiesto además por Kjøller (1991), resaltando lo mítico y lo real, y las múltiples influencias de las organizaciones sociales en el lenguaje de los medios de Dinamarca.

Dos aplicaciones prácticas de los estudios mencionados las constituyen los trabajos de Majkowska (1996), en el que trata los cambios lingüísticos en los medios de comunicación en la transición al capitalismo en Polonia y Svensson y Hedquist (1996), quienes analizan el seguimiento del referendum para la entrada en la Unión Europea de Suecia.

Enlazando con esta última cuestión, hemos de constatar la gran cantidad de investigaciones que analizan las informaciones políticas en los medios. Así, por ejemplo, lo hacen Maarek (1989) para Francia, Svensson (1989) para Suecia y Swinggers y Devlieger (1994) para Bélgica. Gruber (1989) indaga en la manipulación informativa que se da con relación a estos temas. Suecia ha sido el país donde con más frecuencia han aparecido estudios en torno a esta problemática. Así a los arriba ya nombrados, han de sumarse por su importancia los trabajos de Ledin (1995) acerca de los cambios textuales en la prensa democrática derivados de la ascensión de los movimientos obreros, y el de Strand y Resen (1996), que analiza el 
comportamiento lingüístico de los líderes socialdemócratas y de otros partidos en entrevistas electorales televisadas en el período 1964-1991.

Diferentes autores han subrayado que los medios reflejan el punto de vista dominante de una sociedad, la perspectiva del poder (Berruto, 1979: 156; Davis y Walton, 1983; etc.). Al tiempo, el estatus de la variedad estándar confiere un aura de oficialidad al discurso medio del contenido (Fowler, 1991), lo cual frecuentemente induce a no cuestionar estos contenidos. La relación de los medios de comunicación con el poder y cómo éste se expresa en ellos es estudiada por Iglum y Messel (1989) en el contexto noruego y Czuba (1996) en Polonia.

Otro aspecto que debe ser destacado es el del uso del lenguaje políticamente correcto en los medios de comunicación, especialmente en relación con el lenguaje discriminatorio, y, dentro de este, el sexismo o racismo. Un caso paradigmático dentro de los propios medios son las publicaciones que la cadena de televisión australiana $\operatorname{ABC}(1984,1989)$ dedicó a estos temas.

Uno de los temas más investigados en relación con la creación de opinión desde los medios es la influencia ideológico-propagandística en situaciones de conflicto étnico, bien sea en contextos discriminatorios o en situaciones bélicas. Este ha sido un tema recurrente en Alemania, Austria, Holanda, al tratar el antisemitismo en los medios de comunicación (Sauer, 1987; Gruber y De Cillia, 1989; Gruber, 1991; Wodak y Menz, 1994; Wodak et alii, 1994; Gruber y Wodak, 1995). Las tensiones étnicas en los balcanes y sus consecuentes guerras han sido estudiadas por Milinković (1994), y Lalić (1995). Ambos autores hacen un análisis de los contenidos de los medios, los cuales contribuyeron a crear un clima de odio frente a la etnia diferente.

Las tensiones étnicas en los medios se han repetido en otros países. Un estudio de éstas ha sido realizado por Furdik y Niżniková (1989) para Eslovaquia, Nekvapil (1996) se ocupa de la identidad nacional de la República Checa, Dabrowska (1995) señala las tensiones frente a Polonia en la prensa alemana, en tanto que Damjanova (1996) analiza las discriminaciones sociales de los indios en los medios de Guatemala. En otro orden de cosas, Connel Galasinski (1996) muestra cómo la CIA americana se esfuerza a través de Internet por cambiar su mala imagen internacional.

La relación entre el discurso de los medios de comunicación y las funciones de éstos es un tema de singular trascendencia para la sociolingüística. El público suele reconocer la importancia del discurso de los medios, que son, por lo demás, parte de la vida social y constituyen un Cuarto Estado en opinión de Curran y Seaton (1991).

Los medios pueden ser utilizados como instrumentos lingüísticos educativos. En este sentido, J. y L. Milroy (1985) han discutido este papel de los medios en relación con los conceptos de autoridad en el lenguaje y en relación con la corrección y la estandarización linguiística.

Se cuenta con una amplia gama de trabajos que discuten las aplicaciones didácticas del lenguaje de los medios de comunicación. Los procesos de alfabetización en Sudamérica y zonas deprimidas de España, sobre todo a través de la radio, son tratados en Aguaded Gómez (1992, 1993, 1996), Burke (1976) y VV.AA. (1992). Baetens Beardsmore (1985), se ocupa de los procesos de educación bilingüe apoyados en los medios de comunicación, en tanto que, de otra parte, Weingarten (1995) reflexiona acerca del desarrollo de la capacidad comunicativa en alemán a partir de una didáctica basada en la experiencia con los medios de comunicación. El mismo asunto es estudiado por Richard-Zapella (1991) con respecto a la lengua francesa. El uso del lenguaje de los medios de comunicación para la enseñanza y aprendizaje de 
idiomas ha sido una constante en la bibliografía - y en general, en las propuestas educativas de las dos últimas décadas. A modo de ejemplo cabe citar a Leitner (1980b, 1989) para el inglés, Leal (1989) para el portugués, Bjørgen (1987) para el sueco a través de la televisión, Szkudlarczyk (1995) para el chino a través de la prensa, etc.

Por último, cabe citar algunos estudios que tratan de analizar la respuesta de los receptores en el proceso comunicativo de la comunicación mediática. Como indica Leitner (1996: 201), algunos estudios sugieren que los contenidos sobre temas relativos a la lengua indican un sentimiento de identidad y pertenencia lingüística de una comunidad de habla: Leitner (1984) y Reeve (1989) para Australia, Bell (1990) para Nueva Zelanda.

Alternativamente y contradictoriamente, el lenguaje de los medios es visto como un modelo a seguir o como un uso de la lengua a evitar. A un mismo tiempo influye en el cambio lingüístico, y por su poder homogeneizador, elimina los pequeños dialectos (Andrzejewski, 1971).

\section{Bibliografía}

ABC (1993): Libro de estilo de ABC. Madrid.

ABC (Australian Broadcasting Corporation) (1984): Non-sexist Language Guidelines. Sidney. ABC (Australian Broadcasting Corporation) (1989): Thoughts that Glow and Words that Burn: An ABC Guide to Non-discriminatory Language. Sidney.

Abend, M. (1974): "Die Tagesschau: Zielvorstellungen und Produktionbedingungen". Rundfunk und Fernsehen 22: 166-187.

Åbrink, H. (1996): "Radiopratarens ethos" [El ethos del locutor de radio]. En: Ivars, A. M. et alii (eds.): Svenskans beskrivning 21. Lund: 307-316.

Agencia Efe. (1989): Manual de español urgente. Madrid.

Aguaded Gómez, J. I. (1992): Enseñar y aprender con prensa, radio y televisión. Huelva.

Aguaded Gómez, J. I. (1993): Comunicación audiovisual en una escuela renovada: propuestas desde los medios. Huelva.

Aguaded Gómez, J. I. (1996): Comunicación audiovisual en una enseñanza renovada. Huelva.

Albó, X. (1977²): Idiomas, escuelas y radios en Bolivia. La Paz.

Alcoba, S. (1998): Léxico periodístico español. Barcelona.

Alvar, M. (1990): "Medios de comunicación y lingüística". Lingüística Española Actual XII: 151-173.

Andrzejewski, B. W. (1971): "The Role of Broadcasting in the Adaptation of the Somali Language to Modern Needs". En: Whitley, W. H. (ed.): Language Use and Social Change. Londres: 241-252.

Ávila, R. (1988): "Lengua hablada y estrato social: un acercamiento léxico-estadístico". Nueva Revista de Filología Hispánica 36: 131-148.

Ávila, R. (1992): Difusión Internacional del Español por Radio y TeleVisión (DIES-RTV): Procedimiento para recopilar el corpus por países. México D.F. http://www.colmex.mx/paginas_personalizadas/CELL/Ravila/.

Ávila, R. (1994): "El lenguaje de la radio y la televisión: Primeras noticias". En: Alegría, Alonso et al. (eds.): II Encuentro de lingüistas y filólogos de España y México. Salamanca: 102-117.

Ávila, R. (1996): Difusión Internacional del Español por Radio, Televisión y Prensa: Unidad $y$ diversidad de la lengua (DIES-RTP) Proyecto de investigación. México D.F http://www.colmex.mx/paginas_personalizadas/CELL/Ravila/. 
Ávila, R. (1997a): "A radio e a televisão e o desenvolvimiento de normas linguisticas nacionais e internacionais". Revista Internacional de Lingüística Portuguesa 16: 91-98.

Ávila, R. (1997b): "Televisión internacional, lengua internacional". En: VV. AA. (1997).

Ávila, R. (1997c): "Lenguaje, medios e identidad nacional". 49 Congreso Internacional de Americanistas, Quito, Ecuador. Quito. También en: http://www.colmex.mx/paginas_personalizadas/CELL/Ravila/Lenguaje.htm.

Ávila, R. (1997d): "Variación léxica: connotación, denotación, autorregulación". Anuario de Letras XXXV: 77-102. También en: Hueda, H. / Takagaki, T. (eds.) (1997): Varilex 5. Tokio: $13-27$.

Ávila, R. (1997e): "La comunicación masiva y las lenguas en la aldea global". En: Herzfeld, A. / Lastra, Y. (eds.) (1999): Las causas sociales de la desaparición y del mantenimiento de las lenguas en las naciones de América. Trabajos presentados en el 49. Congreso Internacional de Americanistas, Quito, Ecuador, Julio 7-11, 1997. Hermosillo.

Ammón, U. / Mattheier, K. J. / Nelde, P. H. (eds.) (1987-1999): Sociolinguistica. International Yearbook of European Sociolinguistics: Vol. I - XIII. Tübingen.

Baetens Beardsmore, H. (1985): "Medium and Message Orientated Communication Compared with the Bics/Calp Theory in Bilingual Education". En: Debusscher, G. Y / van Noppen, J. P. (eds.): Communiquer et Traduire: hommages à Jean Dierickx. Bruselas: 191-199.

Ball, M. J. (1985): "Radio Cymru: Programme Style and Linguistic Variation". Journal of Multilingual and Multicultural Development 6: 157-163.

Ballstaedt, S. P. (1980): "Nachrichtensprache und Verstehen". En: Kreuzer, H. (ed.): Fernsehforschung und_Fernsehkritik. Göttingen: 226-241.

Ballstaedt, S. P. / Esche, A. (1976): Zur Verständlichkeit von Nachrichtentexten. DFG-Projekt "Nachrichtensprache und der Zusammenhang von Text und Bild". Tübingen.

Balsebre, A. (1994): El lenguaje radiofónico. Madrid.

Bansal, R. / Harrison, J. (1983): Spoken English for India. Madras.

Barahona Novoa, A. (1996): Léxico básico de la radio costarricense. Universidad de Costa Rica, Tesis de maestría inédita.

BBC (British Broadcasting Corporation) (1979): The Quality of spoken English. A report for the BBC by R. Burchfield, D. Donaghue, A. Timothy. Londres.

Bell, A. (1983): "Broadcast News as Language Standard". International Journal of the Sociology of Language 40: 29-42.

Bell, A. (1984a): "'Good Copy - Bad News'. The Syntax and Semantics of News Editing". En: Trudgill, P. (ed.): Applied Sociolinguistics. Londres etc.: 73-116.

Bell, A. (1984b): "Language Style as Audience Design". Language in Society 13: 145-204.

Bell, A. (1990): "Audience and Referee Ddesign in New Zealand Media Language". En: Bell, Allan / Holmes, Janet (eds.): New Zealand Ways of Speaking English. Bristol: 165-194.

Bell, A. (1991): The Language of News Media. (Language in Society). Oxford / Portland.

Bell, A. / Garret, P. (eds.) (1997): Approaches to Media Discourse. Oxford / Portland.

Berruto, G. (1974/1979): La sociolingüística. México D.F.

Berruto, G. (1986): La variabilità sociale della lingua. Turín.

Bing, J. (1991): "Språk og informasjonstjenester" [Lengua y servicios de información]. En: Åstvedt, M. / Andresen, H. (eds.): Kulturens dekningsbidrag. Om internasjonalisering og kulturkunnskap. Oslo: 88-99.

Bjørgen, I. A. (1987): "Språklæring foran TV skjermen". Norsk Pedagogisk Tidsskrift 71/1: 312.

Block, M. (1997): Writing Broadcast News: Shorter, Sharper, Stronger (Revised and Expanded Edition). Chicago.

Block, M. / Durso, J (1999): Writing News for TV and Radio. Chicago. 
Bosshart, L. (1976): "Untersuchungen zur Verstehbarkeit von Radio- und Ferseh-Sendungen". Rundfunk und Fernsehen 24: 197-209.

Bračič, S. (1993): Kommunikative Funktion der gegenwärtigen deutschen Umgangssprache in Pressereiseerzählungen. Umgangsprache als Varietät in schritlichen Texten. Frankfurt am Main.

Braga, G. (1970): Il sistema della communicazione come construto mediatore fra società e linguaggio. Roma.

Burger, H. $\left(1990^{2}\right)$ : Sprache der Massensmedien. Berlín / Nueva York.

Burke, R. C. (1976): El uso de la radio en la alfabetización de adultos. Madrid.

Cardiff, D. (1980): "The 'Serious' and the 'Popular': Aspects of the Evolution of Style in Radio Talk 1928-1939". Media, Culture and Society 2: 29-47.

Carl, B. (1991): "Oppositional Readings of Network Television News: Viewer Deconstruction". Discourse and Society 2: 183-202.

Cebrián Herreros, M. (2000): "El idioma español en la radio". Revista mexicana de comunicación. Fundación Manuel Buendía. http://www.fundacionbuendia.org.mx/rmc/default.html.

Cervignón, J. M. T. y otros. (1977): "Towards a New Radio News Language". Rencontres de Tenerife 3/1976: 219-257.

Connel, I. / Galasinski, D. (1996): "Cleaning up its Act: the CIA on the Internet". Discourse and Society 7: 165-186.

Cortese, G. / Potesta S. (1987): "Strategie di interazione verbale: le donne del parlamento radiofonico". En: Cecioni, C. G. / Del Lungo Camiciotti, G. (eds.): Lingua letteraria e lingua dei media nell'italiano contemporaneo. Florencia: 102-139.

Coupland, N. (1985): "'Hark, Hark, the Lark': Social Motivations for Phonological StyleShiftings". Language and Communication 5/3: 153-171.

Curran J. / Seaton, J. (1991): Power without Reponsibility: The Press and Broadcasting in Britain. Londres.

Czuba, K. (1996). Media $i$ władza [Los medios de comunicación y el poder]. Varsovia.

Dabrowska, J. (1995). "Polen in der deutschen Presse". Sprachreport 3: 1-4.

Damjanova, L. (1996). "Propuesta de mordaza periodística: sobre el lenguaje de prensa y la realidad social en Guatemala". En: Cichon, P. / Hassauer, F. / Kremnitz, G. / Martínez, P. (eds.): Actas de las Primeras Jornadas de Hispanistas en Austria. Viena: 25-34.

Davis, D. K. / Vincent, R. (1986): "Making Sense of Air Disaster News: Viewer Perceptions and Story Content". Belfast Working Papers in Language and Linguistics 8: 190-220.

Davis, H. / Walton, P. (1983): "Death of a Premier: Consensus and Closure in International News". En: Davis, H. / Walton, P. (eds.): Language, Image, Media. Oxford: 8-49.

De la Peña, E. (1982): "El lenguaje de la televisión". En: Comisión para la Defensa del Español: La política lingüística de México. $2^{a}$ parte. México: 1-22.

Del Canto, L. (1987): "La televisión y el habla de los jóvenes". En: Recherches Iberiques et cinematographiques II, 7, enero de 1987. Estrasburgo, CRICS II et Département d'Etudes Ibériques et Latino-Américanes, UFR des Langues et Sciences Humaines Appliquées, Université des Sciences Humaines: 56-63.

Delamotte, E. (1990): "Les industries de la langue: entre l'innovation technologique et les pratiques des utilisateurs". Cahiers de Linguistique Sociale 16: 27-52.

Dhrimo, A. (1990). "Mendime për gjuhën e gazetës 'Fitorja'" [Algunas observaciones sobre el lenguaje del periódico "Fitorja"]. Gjuha jonë 3: 12-20.

Diadori, P. (1992): "La lingua dei telegiornali italiani degli anni '90'". Studi Italiani di Lingüística Teórica e Applicata 21: 229-265.

Diadori, P. (1993): "La lingua dei telegiornali italiani deli agli '90". Rassegna Italiana di Lingüística Applicata 25/2: 107-153.

Diadori, P. (1994): L'italiano televisivo. Roma. 
Diari De Barcelona (1987): Un modell de llengua pels mitjans de comunicació. Barcelona.

Dijk, T. Van (1988a): News and Discourse. Hillsdale, N. J.

Dijk, T. Van (1988b): News Analysis: Case Studies of International and National News in the Press. Hillsdale, N. J.

Dobroczyński, G. (1996): Kultura i media [La cultura y los medios de comunicación]. Varsovia.

Einarsson, J. (1994): "Offentlig privathet i närradion" [Privacidad pública en la radio local]. En: Språkbruk, grammatik och språkförändring. En festskrift till Ulf Teleman 13.1.1994. Lund: 25-36.

El País (1990): Libro de estilo. Madrid.

Ensink, T. (1997): "De vehouding tussen tekst en beeld in televisie-documentaires. Het Reporter-programma van 8 april 1994 over het Arscop-commissariaat val Elco Brinkman" [La relación entre texto e imagen en los reportajes de televisión: El caso del programa de la televisión holandesa 'Reporter' del 8 de abril de 1994, sobre un dirigente político holandés presente en el Consejo de Administración de una compañía sospechosa]. Tijdschrift voor communicatiewetenschap 25, 4: 304-325.

Esquenazy, J. P. (1993): "Journal télévisé et production du pseudovisible". Langage et Societé 64: 73-92.

Estrela, E. (1989): "Lingua e televisão, espelhos da vida e do homem". Actas: 268-279.

Famiglietti, M. (1977): "La lingua dei preadolescenti meridionali tra il 1964 ed il 1974". En: Simone, Raffaele / Ruggiero, Giulianella (eds.) (1977): Aspetti sociolinguistici dell'Italia contemporanea. Atti del'VIII Convegno Internazionale di Studi della SLI. Roma:429-448.

Farago Leonardi, M. (1993): "Giornalese versus giornalistese" [Lenguaje de los periódicos frente a lenguaje de los periodistas]. Rassegna Italiana di Lingüística Applicata 25/3: 149158.

Fasold, R. / Hamada, H. / Robinson, D. / Barish, S. (1990): "The Language Planning Effect of Newspaper Editorial Policy: Gender Differences in The Washington Post". Language in Society 19: 521-540.

Felderer, B. (1990): "Zur sprachlichen Realisation von Höflichkeit in TV-Interviews mit Politikern". En: Wodak, R. / Menz, F. (eds.): Sprache in der Politik - Polotik in der Sprache. Klagenfurt: 208-220.

Ferguson, C. A. (1983): "Sports Announcer Talk: Syntactic Aspects of Register Variation". Language in Society 12: 153-172.

Fiala, P. / Habert, B. (1989): "La langue de bois en éclat: les défigements dans les titres de presse quotidienne française". Mots 21: 83-98.

Fishman, J. (1972): The Sociology of Language. Rowley. (Trad. esp. de: Sarmiento, R. I Moreno, J. C. (1979): Sociología del lenguaje. Madrid).

Fishman, J. (1974): Advances in Language Planning. The Hague.

Földes, C. / Hécz, A. (1995): Deutsche Rundfunksprache in mehrsprachiger Umwelt. Am Beispiel der Verwendung von Phraseologismen. Wien.

Fowler, R. (1991). Language in the News: Discourse and Ideology in the Press. Londres / Nueva York.

Fowler, R. / Hodge, R. / Kress, G. / Trew, T. (1979): Language and Control. Londres.

Fox, T. (1991): The Challenge of Information Technology and Mass Media for Small Linguistic Societies. Education Media International (Número especial) 28, 3.

Frandsen, F. (dir.) (1996): Medierne og sproget [Los medios de comunicación y la lengua]. Ålborg.

French, N. (1986): "Language and the Media. Teanga". Journal of the Irish Association for Applied Linguistics 6: 1-20.

Fritz, G. / Straßner, E. (eds.) (1996): Die Sprache der ersten deutschen Wochenzeitungen im 17. Jahrhundert. Tübingen. 
Furdik, J. / Nižniková, J. (1989). "Z lexiky a syntaxe povstaleckej tlače" [Sobre el vocabulario y la sintaxis en los periódicos editados durante el Alzamiento Nacional Eslovaco]. Slovenská reč 54: 193-206.

García Marcos, F. J. (1995): Actas de las I Jornadas almerienses sobre Política Lingüística. Almería 1990. Almería.

Geest, A. J. Van Der (1995): "De effectiviteit van audiovisuele media in de interne en externe voorlichting" [La efectividad de los medios audiovisuales en la relaciones públicas internas y externas]. En: Mazeland, H. J. / Sauer, C. L. A. (eds.): Communiceren, waarnemen en analyseren. Bijdragen tot het taalbeheersing sonderzoek. Groningen: 121144.

Gheţie, I. (1994): "Rostirea românească la radio" [Forma rumana de expresión en los medios de comunicación]. Limba română XLIII, 1-2: 63-64.

Giacomelli, R. (1992): "Il linguaggio dei giornali giovanili". En: Medici, M. / Proietti, D. (eds.) (1992): 93-95.

Good, C. (1985): Presse und soziale Wirklichkeit. Ein Beitrag zur 'kritischen Sprachwissenschaft'. Sprache der Gegenwart. Düsseldorf.

Graustein, G. / Thiele, W. (1987): Properties of English Texts. Leipzig.

Greatbatch, D. (1986): "Some Standard Uses of Supplementary Questions in News Interviews". Journal of the Irish Association for Applied Linguistics 8: 86-123.

Gruber, H. (1989): "Fachtexte in Politik und Medien - Information oder Manipulation". En: Dressler, W. U. / Wodak, R. (eds.): Fachsprache und Comunication. Viena: 47-67.

Gruber, H. (1991): Antisemitismus im Mediendiskurs. Die Affäre "Waldheim" in der Tagespresse. Wiesbaden.

Gruber, H. (1992): "Rollenstruktur und Konfliktaustragung in einer Fernsehdiskussion". En: Hess-Lüttich, E. W. B. (ed.): Kulturkonflikt - Medienkonflikt - Konflikt in den Medien. Opladen: 317-349.

Gruber, H. / Wodak, R. (1995): "Österreich und seine 'Nazi-Hanseln'. Von massenmedialen Umgang mit Neonazismus und Auschwitzlüge in österreichs auflagenstärkster Tageszeitung". En: Reiher, R. (ed.): Sprache in Konflikt. Berlin: 391-417.

Gruber, H. / De Cillia, R. (1989): "Menschenfresser aller Länder, vereinigt euch! Antisemitische Vorurteile in den österreischischen Medien, 1986" Journal für Sozialforschung 29: 215-243.

GUMG (Glasgow University Media Group) (1980): More Bad News. Londres.

Gutiérrez, F. (1979): Spanish Language Radio in the Southwestern United States. Austin.

Hall, S. (1978): "The Social Production of News". En: Hall, Stuart et alii (eds.): Policing the Crisis: Mugging, the State, and The Law and Order. Londres: 53-77.

Halwachs, D. W. (1991): Persusiver Sprachgebrauch in der Politik. Versuch einer Stilanalyse anhand von TV-Gesprächen. Graz.

Hargreaves, J. (1982): "Sport, Culture and Ideology". En: Hargreaves, J. (ed.): Sport, Culture and Ideology. Londres: 30-62.

Harris, S. (1986): "Interviewers' Questions in Broadcast Interviews". Journal of the Irish Association for Applied Linguistics 8: 50-85.

Hartley, J. (1982): Understanding News. Londres.

Hawkins, P. (1989): "The Gift of the Gab: Factors Affecting Fluency in Radio Interviews". Proceedings of $3^{\text {rd }}$ Symposium of the Description and / or Comparison of English and Greek. Tesalónica: 183-205.

Heinrich, J. R. (1981): "Reader Comprehension of Verb and Subject Headlines". Journalism Quarterly 58: 638-640.

Hess-Lüttich, E. W. B. (1983): "Jugendpresse und Sprachwandel". International Journal of the Sociology of Language 40: 93-105.

Hess-Lüttich, E. W. B. (1987): Angewandte Sprachsoziologie. Stuttgart. 
Hinkelbein, S. (1977): Der Sprechstil bei Fernsehnachrichten und seine Folgen für Verständnis und Meinungsbildung. DFG-Projekt "Nachrichtensprache und der Zusammenhang von Text und Bild". Tübingen.

Hinskens, F. / Keiser, S. H. / Migge, B. / Strand, E. (1997): "The Northern Cities Shift in the Heartland? A Study of Radio Speech in Columbus, Ohio". En: Ainsworth-Darnell, K. I D'Imperio, M. (eds.): Papers from the linguistics laboratory. Ohio State University, Working Papers in Linguistics 50. Ohio: 41-68.

Hlavsa, Z. (1990): "K jazykovědné analýze komunikace v hromadných sdělovacích prostředcích" [Sobre el análisis lingüístico de la comunicación en los medios de masas]. Slovo a slovesnost 51: 124-130.

Holly, W. (1992): "Die Samstagabend-Fernsehshow. Zu ihrer Medienspezifik und ihrer Sprache". Muttersprache 102: 15-36.

Holly, W. / Püschel, V. (1996): Sprache und Fernsehen. Heidelberg.

Holly, W. / Hühn, P. / Puschel, U. (1986): Politische Fernsehdiskussionen. Zur medienspezifischen Inszenierung von Propaganda als Diskussion. Tübingen. (=Medien in Forschung und Unterricht, Serie A, 18).

Huertas Bailén, A. (1999): Redacción y locución en medios audiovisuales: la radio. Barcelona.

Hussein R. F. / Zughoul, M. R. (1993): "Lexical Interference in Journalistic Arabic in Jordan". Language Sciences 15: 239-254.

Hutchby, I. (1996): "Power in Discourse: the Case of Arguments on a British Radio Talk Show". Discourse and Society 7: 481-497.

Huth, L. (1977): "Ereignis, Objektivität und Präsentation in Fersehnachrichten". En: Friedrich, H. (ed.): Kommunikationsprobleme bei Fernsehnachrichten. Tutzing: 103-123.

Hutz, L. y otros (1977): "Nachrichten sehen - Nachrichten verstehen - Nachrichten verwenden. Zu einem neuren Ansazt der Rezeptionsanalyse". Publizistik 22: 403-418.

Iglum, L. / Messel, A. (1989): "Skjultemaktprosesser i massenkomunikasjon" [Procesos de poder disimulados en los medios de comunicación]. Spesialpedagogiske forskningsbidrag. Statens spesiallærerhøgskole, XII. Oslo: 156-176.

Jansen, D. / Verhoeven, G. (1995): "Fallacies in Newspapers and Magazines; towards an Inductive Approach and Discoveries". En: Van Eeemeren, F. H. / Grootendorst, R. / Blair, J. A. / Willard, C. A. (eds.): Reconstruction and Application. Proceedings of the Third ISSA Conference of Argumentation. Estocolmo: 535-543.

Jocić, M. (1985): "Istraživanje jezika u masovnim medijima" [Investigaciones en el lenguaje de los medios de comunicación]. Novinarstvo XXI, 3-4: 213-219.

Jonsonn, Å. (1989): "Språkvård i praktiken. Norm och tradition i etermediernas språk" [Cultural lingüística en práctica. Norma y tradición en el lenguaje de los medios de comunicación]. Språket i massmedierna. En antologi från Nordicom-Sverige 3-4 / 89. Göteborg: 61-73.

Jonsonn, À. (1989): Etermedierna och språket. Rapport från en Konferens på Sveriges Radio april 1989 [La lengua en los medios de comunicación. Actas de una conferencia en la Swedish Broadcasting Corporation, Abril de 1989]. Estocolmo.

Jucker, A. (1992): Social Stylistics: Sintactic Variation in British Newspapers. Berlín.

Kjøller, K. (1991): Ud ma' sproget. Myter og virkelighed $i$ sprog, medier og organisationer [Habla. Mito y realidad en la lengua, medios y organizaciones]. Copenhague.

Klein, G. (1986): Le politiche linguistiche del fascismo. Bolonia.

Kniffka, H. (1980): Soziolinguistik und empirische Textanalyse. Schlagzeilen- und Leadformulierung in amerikanischen Tageszeitung. Tübingen.

Kress, G. (1983): "Linguistic Processes and the Mediation of 'Reality': the Politics of Newspaper Language". International Journal of the Sociology of Language 40: 40-57. 
Kubiszyn-Mędrala, Z. (1992). "100 najczęstszych wyrazów w języku telewizji polskiej" [Las cien palabras más usadas en el lenguaje de la televisión polaca] Zeszyty Naukowe Uniersytetu Jagellońskiego, nr. 996, Prace Językoznaecze 106/1992: 41-61.

Labov, W. (1972): Sociolinguistics Patterns. Philadelphia. (Trad. esp. de: Marinas Herreras, J. M. (1983): Modelos sociolingüísticos. Madrid).

Lalić, L. (1995): Three TV Years in Serbia: The First Year. Belgrado.

Leal, A. (1989): "Os 'mass-media' e o ensino do Português". Actas: 381-394.

Ledin, P. (1995): Arbetarnes är denna tidning: textförän dringar $i$ den tidiga sozialdemokratiska pressen [El periódico pertenece a los trabajadores. Cambios textuales en la primera prensa democrática social]. Estocolmo. (=Acta Universitatis Stockholmiensis, Stockholm Studies in Scandinavian Philology. New Series 20)

Leitner, G. (1979): BBC English und der BBC. Geschichte und soziolinguistische Interpretation des Sprachgebrauchs in einem Massenmedium, Linguistische Berichte. Wiesbaden.

Leitner, G. (1980a): "BBC English and Deutsche Rundfunksprache". International Journal of the Sociology of Language 26: 75-100.

Leitner, G. (1980b): Britische Massenmedien und Massenkommunikation als landeskundlichlinguistischer Gegenstand in der Anglistik und Sekundarstufe II. Trier, Linguistic Agency University of Trier, Series B, Paper 55.

http://www.philologie.fu-berlin.de/ leitner/leitner.html.

Leitner, G. (1983a): Gesprächanalyse und Rundfunkkommunikation. Die Struktur englischerphone-ins. Hidelsheim.

Leitner, G. (1983b): "The Social Background of the Language of Radio". En: Davis, H. / Walton, P. (eds.): Language, Image, Media. Oxford: 50-74.

Leitner, G. (ed.) (1983c): Language and Mass Media. Topical issue of the International Journal of the Sociology of Language 40, 1983.

Leitner, G. (1984): "Australian English or English in Australia". English Worldwide 5: 55-85.

Leitner, G. (1989): BBC English und Englisch lernen mit der BBC. Munich.

Leitner, G. (1992): "International Corpus of English. Corpus Design - Problems and Suggested Solutions". En: Leitner, G. (ed.): New Directions in English Language Corpora. Berlín: 33-64.

Leitner, G. (1996): "The Sociolinguistics of Communication Media". En: Coulmas, F. (ed.): Handbook of Sociolinguistics. Oxford: 187-204.

Ligara, B. (1992): "Najczęstsze wyrazy z języku telewizji polskiej na tle innych prób pisanych i mówionych" [Las palabras más usadas en el lenguaje de la tevisión polaca en el marco de otras formas de expresión escritas y orales]. Zeszyty Naukowe Uniersytetu Jagellońskiego, nr. 996, Prace Językoznaecze 106/1992: 23-40.

Lo, T. / Wong, C. (1990): "Polyglossia in the 'Printed Cantonese' Mass Media in Hong Kong". Journal of Asian Pacific Communication 1: 27-43.

Löwander, B. (1986): Radio, tv och video bland sverige-finsk ungdom. Stocolmo. $(=S R / P U B$, rapport $n r .19)$.

Lucas, A. (1976): Hacia una teoría de la comunicación de masas. Madrid.

Lutz, B. / Wodak, R. (1986): "Verständlichkeit und Verstehen von Nachrichten". Journal für Sozialforschung 2: 233-248.

Lutz, B. / Wodak, R. (1987): Information für Informierte. Verstehen und Verstädlichkeit von Nachrichtensendungen. Viena.

Maarek, P. J. (1989): "Le message télévisé a-t-il besoin du discours politique?". Mots 20: 2342.

Majkowska, G. (1996): "Zajawki, potocyzmy i wtórne nominacje: język prasy w okresie nowego podziału medialnego" [El lenguaje de la prensa en el tiempo de la reestructuración del mercado mediático]. Regiony 3: 109-117. 
Martensson, E. (1989): "Offentliga privatsamtal - modern massmediegenre" [Hablas privadas en público - el género de los medios de comunicación modernos]. Språket i massmedierna. En antologi från Nordicom-Sverige 3-4/ 89. Göteborg: 87-102.

Martensson, E. (1990): "Mediernas intimisering" [La intimación de los medios de comunicación]. Tvärsnitt 1, 34: 34-49.

Martínez Albertos, J. L. (1983): Curso general de redacción periodística. Barcelona.

Martínez Albertos, J. L. (1990): "El uso de la lengua en la comunicación periodística: aspectos culturales, políticos y sociales". Lingüística Española Actual 12/2: 175-196.

Mcchesney, R. A. (1989): "Media Made Sport: a History of Sport: a History of Sports Coverage in the United States". En: Wenner, L. (ed.): Media, Sports and Society. Newbury Park: 49-69.

Mcquail, D. (1983): Mass Communication Theory. An Introduction. London. (Trad. esp. de: Desmonts, A. J. (1985): Introducción a la teoría de la comunicación de masas. Barcelona).

Medici, M. / Proietti, D. (eds.) (1992): Il linguggio del giornalismo. Milán.

Milinković, B. (ed.) (1994): Hate Speech: An Analysis of the Contents of Domestic Media in the First Part of 1993. Belgrado.

Milroy, J / Milroy, L. (1985): Authority in Language: Investigating Language Prescriptivism and Standardization. $2^{\text {a }}$ ed. 1991. Londres.

Mislovičová, S. (1994): "Špecificá športových komentárov v televízii" [Las particularidades de los comentaristas deportivos en televisión]. Varia 3: 89-96.

Montgomery, M. (1988): "D-J Talk". En: Coupland, Nikolas (ed.): Styles of Discourse. Londres/Nueva York: 85-104.

Moore, D. (1989): "The Sociolinguistics of Guatemalan Indigenous Languages and the Effect on Radio Broadcasting". Ohio. http://ns4.net/patepluma/central/guatemala/guatlg1.html.

Moreno Fernández, F. (1990): Metodología sociolingüística. Madrid.

Muller, F. E. (1995): "Trilogue et 'double articulation' de la conversation radiophonique". Le trilogue: 201-223.

Nekvapil, J. (1996): "Tschechische Medien und Mediensprache nach dem Regimewechsel". En: Mänicke-Gyöngyösi, K. (ed.): Öffentliche Konfliktdiskurse um Restitution von Gerechtigkeit, politische Verantwortung und nationale Identität. Frankfurt am Main: 93118.

Nihalani, P. / Tongue, R. / Hosali, P. (1979): Indian and British English: A Handbook of Usage and Pronunciation. Nueva Delhi.

Noelle-Neumann, E. / Schulz, W. / Wilk, J. (eds.) (1994 $\left.{ }^{4}\right)$ : Fischer Lexikon PublizistikMassenkommunikation. Frankfurt am Main.

Nordberg, K. (1992): "Mot en ny muntlighet? Tal, teknik, tradition i svensk radio" [Hacia una nueva oralidad. Lenguaje, técnica y tradición en la radio sueca]. En: Lundström, J. E. I Sahlström, B. (eds.): Talspråk, skriftspråk, bildspråk. Linköping: 127-141. (=Estudios de Comunicación 35).

Nordberg, K. (1992): "Uppbrott från monologen: Om Kvinnliga uttrych i radion" [Fuera del monólogo: Sobre las formas femeninas de expresión en la radio]. Tvärsnitt 3: 12-35.

Nordisk Språksekretariat (1989): Nordisk tv-teksting [Subtitular en los programas de la televisión nórdica]. Rapport 12. Oslo.

Nuolijärvi, P. / Tiittula, L. (1995): Vuorovaikutus televisiokeskustelussa. Projektin taustaa ja lähtökohtia [Interacción en la conversación en televisión]. Helsinki. (=Tutkimus-raportti 8/1995).

Nuolijärvi, P. (1997): Televisiokeskustelun agenda [Agenda en la conversación en televisión]. Helsinki. (=Tutkimukset 1/1997).

Omdal, H. (1995): "Med språket på flyttebot i mediaderen" [Emigrar con tu dialecto nativo a un entorno de medios de comunicación]. En: Alsnes, R. (ed.): Kan tale speglast? 
Kompendium frå ein tverrfagleg konferanse om språket $i$ etermedia, språkhaldningar og språkleg påverknad. Oslo, 20-21. April. 1995. Oslo: 75-99.

Ortega Olivares, J. (1979): Aspectos léxico-estadísticos del español hablado en televisión. Granada.

Paananen, R. (1996): "Radio rentoutuu - Kirjakielestä puhekieleen" [Lenguaje radiofónico del lenguaje estándar a las variedades lingüísticas habladas]. Kielen Kannoilla: Kotimaisten kielten tutkismuskeskus 20: 41-52.

Palsbro, L. (1995): "En dansker og en spanier sad og så en TV-reklame" [Un danés y un español estaban viendo un anuncio publicitario de televisión]. Sprint, 1, 1995: 12-20.

Papper, R. (1994): Broadcast News Writing Stylebook. Needham Heights.

Patráš, V. (1996): "Problém kómerčnosti a profil komunikácie v neštátnej rozhlasovej sfére" [El problema de la comercialización y el perfil de la comunicación en la esfera radiofónica no estatal]. Patráš I: 159-167.

Pavlou, P. (1997): "The Use of the Cypriot Dialect in the Cyprus Broadcasting Cooperation Commercials". Studies in Greek Linguistics, Proceedings of the $17^{\text {th }}$. Annual Meeting of the Department of Linguistics, Faculty of Philosophy, Aristotle University of Thesaloniki, April, 1996.: 617-627.

Penz, H. (1994a): "Fragen als Mittel der Gesprächssteuerung in amerikanischen FernsehTalkshows". En: Halwachs, D. / Stütz, I. (eds.): Sprache - Sprechen - Handeln. Tübingen: 139-144.

Penz, H. (1994b): Control in American TV Talk Shows: An Analysis of Linguistic Strategies. Graz.

Penz, H. (1996). Language and Control in American TV Talks Shows. An Analysis of Linguistic Strategies. Tübingen.

Petrović, V. (1989a): "Novinski komentar u svetlu jezičkih procesa u novinama" [Los comentarios periodísticos a la luz de los procesos lingüísticos en la escritura periodística]. Književni jezik 18:3: 149-156.

Petrović, V. (1989b): Novinska frazeologija [Fraseología de los periódicos]. Novi Sad.

Považaj, M. (1993): "Sonda do jązyka televízneho spravodajstva" [Una sonda en el lenguaje de la información televisiva]. Kultura slova 27: 38-46.

Raffaelli, S. (1994): "Il parlato cinematografico e televisivo". En: Serianni, Luca / Trifone,

Pietro (eds.): Storia della lingua italiana. Torino: 271-290.

Reeve, J. (1989): "Community Attitudes to Australian English". En: Collins, P. / Blair, D. (eds.): Australian English: The Language of a New Society. St Lucia: 111-126.

Richard-Zappella, J. (1991): "Les mediá comme objets sociolinguistiques depuis 1985". Sociolinguistique Didactique du Français Langue Etrangère. Cahiers de Linguistique Sociale: $139-152$.

Rojas, E. M. (1989): "Norma y uso de la lengua a través de la prensa escrita argentina". Anuario de Lingüística Hispánica 4: 275-285.

Roksvold, Th. (1989). Retorikk for journalister [Retórica de los periodistas]. Oslo.

Roncagliolo, R. (1997): "El lenguaje de la radio: comunidad y globalidad". En: VV.AA. (1997).

http://cvc.cervantes.es/obref/congresos/zacatecas/radio/ponencias/ronca.htm

Romo, C. (1997): "El lenguaje seductor de la radio". En: VV.AA. (1997). http://cvc.cervantes.es/obref/congresos/zacatecas/radio/ponencias/romo.htm

Rubin, A. M. (1986): "Television, Ageing and Information-seeking". Language and Communication 6: 125-138.

Ruf, A. (1996): 'Yi canny talk right': Eine soziolinguistische Untersuchung zur Verwendung des Glaswegian am BBC Radio Scotland und Radio Clyde. Berna. (=Europäische Hochschulschriften, XIV: Angelsächsische Sprache und Literatur 312).

Sadow, C. / Sather, E. (1998): Talk Radio. Massachusetts. 
Sambor, J. (1986): "Nowomowa -język naszych ozasów (El lenguaje de las noticias -El lenguaje de nuestro tiempo)". Poradnik Jezzykowy 6: 365-377.

Sandøy, H. (1996): "Språlegnorm og språleg fridom i norske etermedia" [Norma lingüística y aceptación variacional en la radio y televisión noruegas]. Årsberetning 1994-1995: 33-39.

Sauer, Ch. (1987): "Stil, NS-Propaganda und Besatzungspresse. Die Rubrik 'Spiegel der Woche' in der 'Deutschen Zeitung in der Niederlanden'". Muttersprache 97/1-2: 79-108.

Scannel, P. (ed.) (1991): Broadcast Talk. Londres.

Schmitz, U. (1987): "Sprache und Massenkommunikation". En: Ammon, Ulrich / Dittmar, Norbert / Mattheier, Klaus J. (eds) (1987): Soziolinguistik. Ein internationales Handbuch zur Wissenschaft von Sprache und Gesellschaft. Berlin/New York: 821-833. (=Handbücher zur Sprach- und Kommunikationswissenschaft 3.1).

Schmitz, U. (1995): "Neue Medien und Gegenwartssprache. Lagebericht und Problemskizze". OBST 50: 7-51.

Schramm, W. (1975): Mass Communications. Urbana.

Siehr, K. H. (1993): "Abwickeln: brisantes Wort - brisanter Diskurs". Sprache und Literatur 72: $31-42$.

Simmler, F. (1991): "Die Textsorte 'Regelwerk' und 'Lehrbuch' aus dem Kommunikationbereich des Sports bei Mannschaftensspielen und ihre Funktionen". Sprachwissenschaft 16: 251-301.

Simmler, F. (1993): "Zeitungssprachliche Textsorten und ihre Varianten. Untersuchungen anhand vor regionalen und überregionalen Tageszeitung zum Kommunikationsbereich des Sports". En: Simmler, F. (ed.): Probleme der funktionalen Grammatik. Frankfurt am Main: 133-282.

Simon, J. M. (1987): Guatemala: Eternal Spring, Eternal Tyranny. New York.

Simpson, E. (1985): "Translating in the Nigerian Mass Media: a Sociolinguistic Study". En: Ugboajah, F. O. (ed.): Mass Communication, Culture and Society in West Africa. Múnich: 133-151.

Slembek, E. (1995): "Rhetorische Kommunikation in der Ausbildung von Medienschaffenden". En: Herbig, A. (ed.): Konzepte rhetorischer Kommunikation. St. Ingbert: $25-40$.

Sliwiński, W. (1986): "Dobór elementów językowych w wypowiedziach telewizyjnych (La elección de los medios lingüísticos en los comentarios de televisión)". Przekonania $i$ Opinie.

Sobrero, A. (1971): "Effeti linguistici die mezzi di communicazzione di masa". Parole e Metodi 2: 167-189.

Sorenson, J. (1991): "Mass Media and Discourse on Famine in the Horn of Africa". Discourse and Society 2: 223-242.

Spolsky, B. (1998): Sociolinguistics. Oxford.

Staczek, J. (1993): "The English Language and the Gulf War: Corpus Linguistics, Variation, and Word-formation". World Englishes 12: 15-24.

Stewart, S. O. (1981): "Language in Guatemala: Planning and Prospects". Linguistic Reporter Vol 23 \#7: 6-7.

Stewart, S. O. (1984). "Language Planning and Education in Guatemala". International Education Journal 1: 21-37.

Stoikov, L. (1987): "Stilni polemićni figuri v publisistikata na Engels" [Algunas figuras polémicas refinadas en el periodismo político de Engel]. Godišnik na Sofiiiskija universitet "Kliment Ohridski", Fakultet Žurnalistika, 78, 5: 135-147.

Strand, H. (1991): "Kön, kontext och språklig dominans i TV" [Sexo del presentador, contexto, y dominio interaccional en televisión]. Arkivet för ljud och bild: 7-41.

Strand, H. (1992): Projektet Språklig Kommuniikation och interaktion $i T V$. Metodbeskrivning. [El proyecto de investigación 'Comunicación lingüística e interacción 
en televisión'. Método.]. Institutionen för journalistik, medier och kommunikation. Universidad de Estocolmo, Estocolmo.

Strand, H. / Resén, Ch. (1996): "Socialdemokratiska och andra partiledares språkliga beteende i TV-sända valintervjuer 1964-1991" [El comportamiento lingüístico de los socialdemócratas y de otros líderes partidistas en las entrevistas electorales transmitidas por televisión en el período 1964-1991]. En: Åsard, E. (ed.): Makten, medierna och myterna. Sociademokratiska ledare från Branting till Carlsson. Estocolmo: 254-303.

Straßner, E. (ed.) (1975): Nachrichten: Entwicklungen, Analysen, Erfahrungen. München.

Straßner, E. (ed.) (1982): Fernsehnachrichten: eine Produktions-, Produkt- und Rezeptionsanalyse. Tübingen.

Straßner, E. (ed.) (1997a): Zeitschrift. Tübingen. (=Grundlagen der Medienkommunikation 3). Straßner, E. (ed.) (1997b): Zeitung. Tübingen. (=Grundlagen der Medienkommunikation 2).

Suarez, J. A. (1983): The Mesoamerican Indian Languages. Cambridge.

Svensson, J. (1989): "Riksdagsspråk i TV-åldern" [Retórica parlamentaria en la época de la televisión]. En: Larsson-Krieg, S. (ed.): Tilltalande tal. Estocolmo: 53-61.

Svensson, J. / Hedquist R. (1996): Den problematiska informationen. Dagspressens bevakning av EU-frågan inför folkomröstningen [La información problemática. La covertura de la prensa diaria del asunto de la UE antes del referéndum]. Stylrelsen för psykologisc försvar. Rapport 194/4. Estocolmo.

Swinggers, P. / Devlieger, B. (1994): "Le débat politico-linguistique en Belgique entre 1840 et 1850: analysé dún corpus de périodiques". En Vielle, C. / Swiggers, P. / Jucquois, G. (ed.): Comparatisme, mythologies, langages. En hommage à Claude Lévi-Strauss. Louvain - la - Neuve: 381-425. (=Bibliothèque des Cahiers de l'Ínstitut de Linguistique de Louvain 73).

Szkudlarczyk, W. (1995): Chiński język prasowy: podręcznik - antologia. [Lenguaje periodístico chino: Manual - Antología]. Poznań.

Treskova, S. I. (1989): Problemas sociolingüísticos de los medios de comunicación [en ruso]. Moscú.

Triandafyllidon, A. (1995): "The Chernobyl Accident in the Italian Press: a 'Media StoryLine'". Discourse and Society 6: 107-131.

Trösser, M. (1983): "Rundfunkmoderation bei Beteiligungdssendungen - im Spannungsfeld zwischen Offenheit und Kontrolle". International Journal of the Sociology of Language 40: 77-91.

Tsonev, P. y otros (1996): "Za televizionija ezik" [Sobre el lenguaje de la televisión]. Nauchn. VVOU "V. Levski" 34/1: 191-197.

Utterback, A. S. (1995): Broadcast Voice Handbook: How to Polish Your On-Air Delivery. Chicago.

Vagle, W. (1990): Radiospråket - talt eller skrevet? Syntaktiske og pragmatiske tilnarminger $i$ semiotisk perspektiv [El lenguaje radiofónico - ¿oral o escrito? Aproximaciones sintácticas y pragmáticas a la perspectiva semiótica]. Oslo. (=Oslo-studier i språkvitenskap б).

Vagle, W. (1991): "Radio Language - Spoken or Written?". International Journal of Applied Linguistics 1:1: 118-131.

Valić Nedeliković, D. (1997a): "Psovke u sredstvima masovnog komuniciranja" [Juramentos en los medios de comunicación]. Kultura 95: 101-117.

Valić Nedeliković, D. (1997b): Rikošet reči - jezička analiza redijskih izveštaja s ratišta / Ricocheting words - A linguistic analysis of radio reports from the battlefields. Belgrado.

Vaquero, M. (1990): "Anglicismos en la prensa. Una cala en el lenguaje periodístico de San Juan". Lingüística Española Actual 12/2: 275-288. 
Videnov, M. (1987): "Rolj jazikovoi kultukj v Bulgarii" [El papel de la corrección lingüística en los medios de comunicación en Bulgaria]. Razvitie jazikovoi žizni stran socialistićeskogo sodružestva 2: 569-576.

VV. AA. (1985a): Radio y escuela. Barcelona. (=Cuadernos de Pedagogía $\left.n^{\circ} 123\right)$.

VV. AA. (1985b): Vybrané otázky jazykové kultury rozhlasového vysílání II (Preguntas selectas de la cultura lingüística de las emisoras de radio II). Praga.

VV. AA. (1989): Språket i massmedierna. En antologi från Nordicom-Sverige 3-4/ 89 [La lengua en los medios de comunicación. Una antología de Nordicom-Sweden]. Göteborg.

VV. AA. (1992): Alfabetización y postalfabetización a través de la radio. Madrid.

VV. AA. (1997): Intervenciones en el Primer Congreso Internacional de la Lengua Española. Zacatecas. http://cvc.cervantes.es/actcult/congreso/.

Wagn, A. H. (1989): "Språkbruk i u-lands-journalistikk" [Uso lingüístico en el periodismo del tercer mundo]. En: Vaage, O. F. (ed.): Massenmedier og u-landsdekning. Oslo: 87-94.

Walton, P. / Davis, H. (1983): "Death of a Premier: Consensus and Closure in International News". En: Davis , H. / Walton, P. (eds.): Language, Image, Media. Londres: 76-99.

Weber, A. (1989): "Zweierlei Deutsch im Rundfunk? Eine vergleichende morphosyntaktische Untersuchung zum deutsch-deutschen Sprachgebrauch". Muttersprache 99: 17-26.

Weingarten, R. (1995): "Kommunikation der Medienerfahrung. Überlegungen zur Entwicklung und Didaktik einer kommunikativen Fähigkeit". Der Deutschunterricht 47/1: 84-92.

Werlich, E. (1976): A Text Grammar of English. Heidelberg.

Wodak, R. / Menz, F. (1994): "Medienberichttersttatung zum Gedenkjahr 1988: der Novenberpogrom in den Fernsehnachrichten des ORF". En: Thalmann, R. (ed.): Nationalismes, Féminismes, Exclusions. Frankfurt: 357-372.

Wodak, R. / Mitten, R. / Stern, F. (1994): Die Sprachen der Vergangenheit. Öffentliches Gedenken in österreinischen und deutschen Medien. Frankfurt.

Wożniakowski, H. (1996): "Media i konflikty w kulturze" [Medios de comunicación y conflictos intraculturales]. Znak 5: 130-134.

Zilbert, B. A. (1986): Soziolinguistische Untersuchung von Texten aus Radio, Fernsehen und Zeitungen. Saratov. 